\title{
Dose-Dependent Prognostic Effect of Carvedilol in Patients With Chronic Heart Failure:
}

Special Reference to Ranscardiac Gradient of Norepinephrine

Keizo Nishiyama, MD; Takayoshi Tsutamoto, MD; Masayuki Yamaji, MD;

Chiho Kawahara, MD; Takashi Yamamoto, MD;

Masanori Fujii, MD; Minoru Horie, MD

(Circ J 2009; 73: 2270-2275)

We at the Editorial Office would like to deeply apologize to the authors and our readers for misspelling the sub-title of this manuscript.

The correct sub-title is "Special Reference to Transcardiac Gradient of Norepinephrine". 